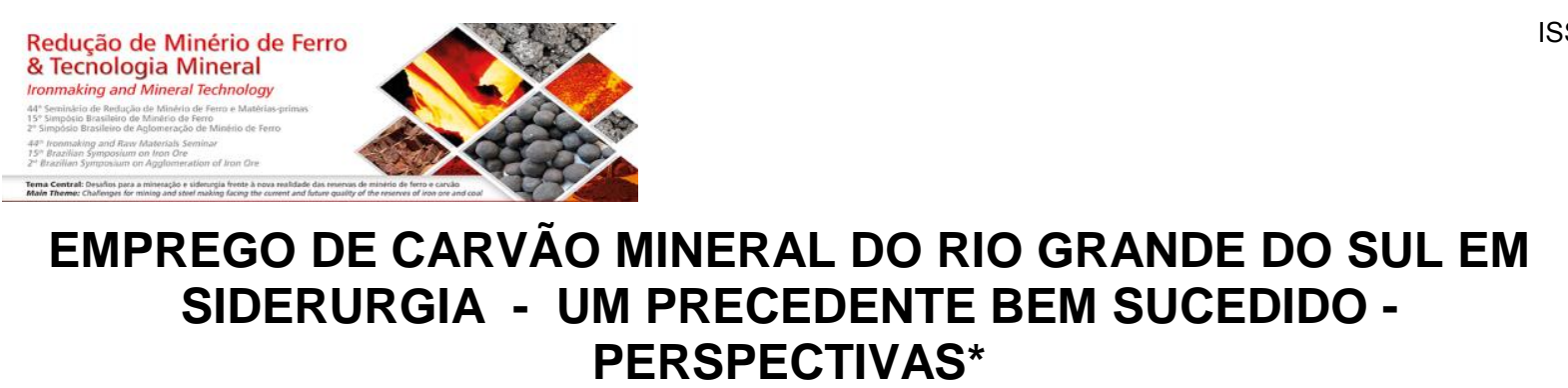

\title{
EMPREGO DE CARVÃO MINERAL DO RIO GRANDE DO SUL EM SIDERURGIA - UM PRECEDENTE BEM SUCEDIDO - PERSPECTIVAS*
}

\author{
Sérgio Wilibaldo Garcia Scherer ${ }^{1}$ \\ Henrique Carlos Pfeifer ${ }^{2}$ \\ Alexandre Balinski ${ }^{3}$ \\ Edson Paulo Menezes ${ }^{4}$ \\ Antônio Cesar Faria Vilela ${ }^{5}$ \\ Gunther Bantel ${ }^{6}$
}

\section{Resumo}

O Balanço Energético Nacional do MME informa que em 31/12/2012, o carvão mineral representa $73 \%$ dos recursos e reservas nacionais de energia fóssil. A partir de 1960 foram realizados estudos e experiências que resultaram na implantação da Aços Finos Piratini (AFP), uma mini usina integrada para aços especiais pela rota tecnológica "Redução Direta a redutor sólido / Aciaria Elétrica", na cidade de Charqueadas/RS. A unidade SI/RN (forno rotativo) operou de 1973 a 1990, com carvão local com até $35 \%$ de cinza. O processo atraiu a atenção mundial: em 1974 foi feito um teste industrial bem sucedido com linhito briquetado alemão; em 1975 o ILAFA realizou em Porto Alegre seu Seminário Internacional sobre Redução Direta; equipes da África do Sul e da Índia foram treinadas na AFP. A Índia é atualmente a líder mundial na produção de ferro esponja a carvão. O trabalho apresenta um modelo de usina integrada, autosuficiente em redutor e energia elétrica, à base de carvão não coqueificável, produzindo tarugos. Além disso, apresenta outras possibilidades de emprego do carvão mineral nacional em siderurgia, tais como a injeção de finos nos altos fornos e seu emprego no processo COREX. As perspectivas futuras estão delineadas em documento do Centro de Gestão e Estudos Estratégicos (CGEE) do MDIC, que coloca metas para 2022 e 2035.

Palavras-chave: Redução direta; Ferro esponja; Redutor sólido; Injeção de finos.

\section{THE USE OF COAL FROM RIO GRANDE DO SUL IN STEELMAKING - A WELL SUCCEEDED PRECEDENT - OUTLOOK}

\begin{abstract}
The National Energy Balance from MME informs that on 31/12/2012 mineral coal accounts for $73 \%$ of national resources and reserves of fossil energy. Since 1960 studies and experiments have been carried through that resulted in the construction of Acos Finos Piratini (AFP), an integrated mini steel plant for special steels, by the technological route "Coal based Direct Reduction / Electric Steelmaking" in Charqueadas/RS. The SI/RN unit (rotary kiln) operated from 1973 through 1990, with local coal with up to $35 \%$ ash. The process attracted worldwide attention: in 1974 a successful industrial test was carried out with German lignite briquettes; in 1975, ILAFA conducted its International Seminar on Direct Reduction, in Porto Alegre; teams from South Africa and India have been trained in AFP. India is currently the world leader in the production of coal based sponge iron. The paper presents a model of an integrated steel plant, self-sufficient in reducing agent and electric energy, based on non-coking coal, producing billets. Moreover, it presents other possibilities of using national mineral coal in steelmaking, such as pulverized coal injection into blast furnaces, or its use in the COREX process. The future prospects are outlined in a document of the Centro de Gestão e Estudos Estratégicos (CGEE), of MDIC, defining targets for 2022 and 2035.

Keywords:Direct Reduction; Sponge Iron; Solid Reducing Agent; Pulverized Coal Injection.

1 Eng. Mecânico e Metalúrgico, Ex-Gerente de Materiais e de Expansão, Aços Finos Piratini S.A., Consultor e Sócio da MINITEC (ex-KTS), Divinópolis, MG, Brasil; scherer@minitec.eng.br.

2 Eng. Mecânico e Metalúrgico, Ex-Diretor Técnico, Aços Finos Piratini S.A., Diretor e Sócio da MINITEC (exKTS), Divinópolis, MG, Brasil; pfeifer@minitec.eng.br.

3 Eng. Metalúrgico, Ex-Gerente da Usina, Aços Finos Piratini, membro do CONSIDER, Brasília, DF, Brasil; rbalinski@vie-rs.net.

4 Eng. Metalúrgico, Ex-Gerente da Unidade de Redução Direta, Aços Finos Piratini S.A., Charqueadas, RS, Brasil; edsonpaulo@terracom.br; edson.paulo@gmlsteel.com.

5 Prof. Dr. Eng. Metalúrgico, LaSid - Laboratório de Siderurgia do Centro Tecnológico, EE, UFRGS, Porto Alegre, RS, Brasil; vilela@ufrgs.br.

6 Eng. Metalúrgico, ex-diretor industrial da Aços Finos Piratini, ex-diretor de Meio Ambiente da COSIPA, Brasil.
\end{abstract}

* Contribuição técnica ao 44ํㅗㄴ Seminário de Redução de Minério de Ferro e Matérias-primas, 15은 Simpósio Brasileiro de Minério de Ferro e $2^{\circ}$ Simpósio Brasileiro de Aglomeração de Minério de Ferro, 15 a 18 de setembro de 2014, Belo Horizontes MG, Brasil. 


\section{INTRODUÇÃO}

Em 31/12/2012, o Balanço Energético Nacional do MME informava que os Recursos e Reservas Energéticas Brasileiras, em petróleo, gás natural e carvão mineral, somam 9,52 bilhões de toneladas equivalentes de petróleo (TEP), sendo 21,6\% na forma de petróleo, 4,6\% de gás natural e 73,8\% de carvão mineral.

A partir de 1960 foi constituído no Rio Grande do Sul um Grupo de Trabalho para elaborar o projeto de uma Mini Usina Siderúrgica Integrada, onde o carvão mineral local não coqueificável fosse usado como redutor. Tratava-se da Aços Finos Piratini S.A. (AFP), usina de aços especiais, com capacidade inicial de 100.000 t/a de aços especiais longos e forjados, a alcançar no futuro a capacidade de $200.000 \mathrm{t} / \mathrm{a}$. A produção atual da usina é de cerca de 500.000 t/a. A Mini Usina contaria com uma unidade de beneficiamento de carvão e uma unidade de redução direta a redutor sólido, com forno rotativo - Processo SL/RN. A AFP foi implantada e a unidade de redução direta operou do final de 1973 até 1990, quando foi desativada, com minério de ferro e pelotas com cerca de $66 \%$ de Fe, e com carvão redutor de cerca de $40 \%$ de $\mathrm{C}_{\text {fix }}, 25,5 \%$ de $\mathrm{MV}, 34,5 \%$ de cinza e umidade de $12,5 \%$. O ferro esponja produzido tinha cerca de $91 \%$ de $\mathrm{Fe}_{\text {tot }}, 82 \%$ de $\mathrm{Fe}_{\text {met }}$ e metalização de cerca de $90 \%$.

O emprego de carvão não coqueificável de alto teor de cinza como redutor, pela primeira vez em escala industrial, suscitou interesse na siderurgia mundial e, em maio de 1975, o ILAFA realizou em Porto Alegre um Seminário sobre "Redução de Minério de Ferro: Estágio Atual e Perspectivas", juntamente com o III Simpósio da ABM sobre eletro siderurgia.

No final de 1974 um grupo de empresas alemãs enviou para a AFP 5.000 t de briquetes de linhito que foram testadas como redutor no forno SL/RN. Entre 3 e 19 de dezembro de 1974 foram produzidas $2.800 \mathrm{t}$ de ferro esponja com pelotas brasileiras e briquetes de linhito da Alemanha, com metalização média de $94 \%$.

Hoje há diversos países, como o Peru, Nova Zelândia, Africa do Sul e principalmente a Índia, produzindo ferro esponja, em fornos rotativos, com redutor sólido.

Este trabalho apresenta diversas tecnologias, comprovadas ou em desenvolvimento, de utilização do carvão não coqueificável do RS em siderurgia.

(a) A tecnologia da AFP: apresenta-se um modelo de usina siderúrgica integrada, com base na bem sucedida experiência da AFP, com as seguintes características: Produção de semiacabados de aço de 1,2 milhões de t/a, a partir de uma carga metálica de 1,49 milhões de t/a, sendo 0,97 mt/a de ferro esponja e 0,52 de outros metálicos.

Para produção de 970.000 t/a de ferro esponja são necessárias 1,1 milhões de t/a de carvão redutor, obtidas do beneficiamento de 3,14 milhões de toneladas de carvão run of mine (ROM). No beneficiamento do carvão ROM são produzidas também 1,1 milhões de t de carvão termelétrico de $3.100 \mathrm{kcal} / \mathrm{kg}$.

Uma usina termelétrica (UTE) de $145 \mathrm{MW}$ poderá ser instalada a partir das 1,1 milhões de t/a de carvão termelétrico, enquanto outra UTE, de $56 \mathrm{MW}$, poderá operar com os gases de saída dos fornos rotativos. Com isso, a usina siderúrgica será integralmente autosuficiente em termos de redutor e de energia elétrica.

Tendo em vista as reservas de carvão não coqueificável do RS o horizonte do modelo proposto, usando a tecnologia desenvolvida na AFP, é bastante superior a 100 anos.

(b) Trabalhos do LaSid da EEUFRGS, alguns em colaboração com a Universidade Técnica de AACHEN/Alemanha, demonstram a possibilidade de injeção de finos de carvão não coqueificavel do RS pelas ventaneiras dos altos fornos a coque, em substituição, ainda que parcial, de carvões importados. 
(c) Também já foi usado carvão não coqueificável do RS, em mistura com carvão metalúrgico de Santa Catarina, em teste industrial na unidade de demonstração do Processo KR, hoje COREX, em Kehl/Alemanha, em 1987, com inteiro sucesso.

As perspectivas de emprego do carvão mineral não coqueificável do $\mathrm{RS}$ em siderurgia estão comprovadas, razão pela qual o CGEE - Centro de Gestão e Estudos Estratégicos do MDIC, em documento de novembro de 2012, colocou metas para a sua utilização, com horizonte até 2022 e 2035.

\section{RECURSOS E RESERVAS ENERGÉTICAS BRASILEIRAS}

Tabela 1. Recursos e reservas energéticas brasileiras em 31.12.2012 [1]

\begin{tabular}{|c|c|c|c|c|c|c|}
\hline Energético & Unidade & $\begin{array}{c}\text { Medidas, } \\
\text { Indicadas, } \\
\text { Inventar. }\end{array}$ & Inferidas & Total & $\begin{array}{c}\text { Equivalência } \\
\text { Energética } \\
\left(10^{3} \text { TEP }\right)[2]\end{array}$ & $\%$ \\
\hline Petróleo & $10^{3} \mathrm{~m}^{3}$ & 2.309 .100 & 2.230 .840 & 4.539 .810 & 2.059 .717 & 21,62 \\
\hline Gás Natural & $10^{6} \mathrm{~m}^{2}$ & 436.420 & 482.138 & 916.569 & 433.375 & 4,55 \\
\hline $\begin{array}{c}\text { Carvão } \\
\text { Min[3] }\end{array}$ & $10^{6} \mathrm{t}$ & 25,759 & 6.535 & 32.394 & $7.032 .178[4]$ & 73,83 \\
\hline Total & & & & & 9.525 .279 & 100,00 \\
\hline
\end{tabular}

Fonte: $M M E$

(1) Balanço Energético Nacional 2013 - dados 2012

(2) Calculado sobre reservas medidas/indicadas/inventariadas

Nota: TEP = tonelada equivalente de petróleo. Corresponde a aproximadamente 10 Gcal.

(3) Mais de $80 \%$ das reservas atualmente conhecidas de carvão mineral estão concentradas no Sul do País: Paraná, Santa Catarina e Rio Grande do Sul.

(4) Admitindo recuperação média de $70 \%$ e poder calorífico de $3.900 \mathrm{kcal} / \mathrm{t}$

\section{A UTILIZAÇÃO DO CARVÃO MINERAL NÃO COQUEIFICÁVEL DO RS EM GASEIFICAÇẨO, GERAÇÃO DE ENERGIA ELÉTRICA E COMO REDUTOR EM SIDERURGIA}

A utilização de carvão mineral do RS para gerar energia remonta ao século XIX: há um bairro em Porto Alegre chamado Gasômetro, onde se encontrava a usina que produzia gás de carvão para atender a demanda da cidade, com gás canalizado.

A Conferência Científica do XVI Congresso Anual da ABM, realizado em Porto Alegre, em Julho de 1961, versou sobre "A Gaseificação do Carvão Mineral do Rio Grande do Sul" [2].

Naquela época já estavam sendo construídas as usinas termelétricas de Candiota e Charqueadas, projetadas para o uso do carvão local.

Também se iniciava o projeto Aços Finos Piratini SA, visando a utilização de carvão local como redutor na produção de ferro esponja, a ser utilizado como matéria prima pela mini usina integrada de aços especiais.

\subsection{A Unidade de Redução Direta SL/RN a Redutor Sólido da AFP}

O Projeto AFP estava centrado no uso do carvão mineral local não coqueificável como redutor siderúrgico. Houve um período de estudos e testes, no Brasil e no exterior, visando determinar a lavabilidade dos carvões de Charqueadas, cuja mina de subsolo já fornecia carvão, após beneficiado, para a usina termelétrica lá instalada. 
Entre outros foram estudados os pontos de amolecimento e de fusão da cinza, por serem de grande importância no processo de redução.

A conclusão foi que o Processo SL/RN, constituído por um forno rotativo a redutor sólido, poderia operar com o carvão local, com até 35\% de cinza e poder calorífico de $4.700 \mathrm{kcal} / \mathrm{kg}$.

A equipe da AFP manteve a comunidade metalúrgica informada, via $A B M$, sobre os seus estudos, experiências e resultados:

No XVIII Congresso da ABM - Rio de Janeiro - Julho de 1963 [3];

No XXI Congresso da ABM - Volta Redonda - Julho de $1966[4,5]$;

No XXIV Congresso da ABM - São Paulo - Julho de 1969 [6];

No XXVI Congresso da ABM - Rio de Janeiro - Junho de 1971 [7];

No XXVII Congresso da ABM - São Paulo - Julho de 1972 [8]

Em função disso foi projetada e implantada a mini usina integrada para a produção de aços especiais, integrada por uma unidade de beneficiamento de carvão, uma unidade de redução direta, aciaria elétrica e demais unidades de produção de aços especiais, forjados e laminados.

A unidade de redução direta - processo SL/RN a redutor sólido, com forno rotativo compreendia os seguintes equipamentos principais:

- Forno rotativo, com 50m de comprimento e 3,6m de diâmetro;

- Resfriador rotativo, com 30m de comprimento e 3,0 m de diâmetro.

A unidade iniciou os testes operacionais no $4^{\circ}$ trimestre de 1973 , utilizando inicialmente minério bitolado e, algum tempo após, também pelotas, ambos com cerca de $66 \%$ de ferro, e como redutor o carvão local. (Tabela 2 )

O minério bitolado produzia uma quantidade relativamente grande de finos de ferro esponja, e como a unidade não dispunha de equipamento de briquetagem, a utilização desses finos na aciaria apresentava dificuldades.

Tabela 2. Matérias Primas e Produto da Unidade SL/RN da AFP.

\begin{tabular}{|c|c|}
\hline Item & Análise \\
\hline Minério de Fe & $66 \% \mathrm{Fe}$ \\
\hline Pelotas & $66 \% \mathrm{Fe}$ \\
\hline Carvão Redutor & $\begin{array}{l}\mathrm{C}_{\mathrm{fix}} 40 \% ; \mathrm{MV} 25,5 \% ; \text { Cinza } 34,5 \% ; \\
\text { Umidade } 12,5 \% ; P_{\mathrm{cs}} 4,700 \mathrm{kcal} / \mathrm{kg}\end{array}$ \\
\hline Ferro Esponja & $\mathrm{Fe}_{\text {tot }} 91 \% ; \mathrm{Fe}_{\mathrm{met}} 82 \% ;$ Metalização $90 \%$ \\
\hline
\end{tabular}

Fonte: Seminário do ILAFA - Maio de 1975 - Porto Alegre [9]

Tendo em vista o interesse que a unidade SL/RN da Piratini despertava, em âmbito mundial, em 1975 foram realizados simultaneamente em Porto Alegre os seguintes eventos, com o patrocínio da OEA (Organização dos Estados Americanos):

- Seminário do ILAFA sobre "A Redução de Minério de Ferro: Estado Atual e Perspectivas"; e

- "III Simpósio da ABM sobre Eletro Siderurgia".

Os trabalhos então apresentados estão reunidos em [10,11].

Todos os processos de redução direta então existentes ou em desenvolvimento seja a redutor sólido, seja a redutor gasoso - se fizeram presentes, estabelecendose ampla discussão sobre a produção e usos do ferro esponja, seja em fornos elétricos a arco, seja em convertedores a oxigênio, seja ainda em fornos cubillôs..

No início de 1977, para resolver problemas operacionais e também para testar outros carvões locais, a unidade passou dois anos não só como unidade de produção, mas também de desenvolvimento.

Foram melhorados os controles e a instrumentação, permitindo um melhor controle das vazões de ar e das temperaturas [11,12]. Pelo lado da Academia foi criado no 
Departamento de Metalurgia da EEUFRGS o Laboratório de Redução Direta, atual LaSid - Laboratório de Siderurgia.

Já em 1979 a unidade voltava ao ritmo de 1976, com produção superior a 40.000 t/ano, e em 1980 produziu acima de 50.000 t/ano. Continuou operando até 1990, quando foi desativada, por razões econômicas. Em 1980 as pelotas representavam $47,4 \%$ do custo de produção e o carvão redutor $8,2 \%$ [13]. O custo da logística de abastecimento de minério à usina localizada no interior do RS, a partir de Vitória/ES, tornara-se proibitivo.

A AFP continuou mantendo a comunidade metalúrgica informada sobre a sua experiência [9,14-16].

Os trabalhos realizados na EEUFRGS foram divulgados junto com a formação dos primeiros engenheiros com mestrado, na área de Redução Direta [20].

\subsection{Influência da AFP sobre a Produção de Ferro Esponja a Redutor Sólido}

O fato de produzir ferro esponja de qualidade utilizando um redutor com $35 \%$ de cinza constituiu um fato marcante.

Antes de iniciar a operação a equipe da AFP recebeu treinamento em algumas empresas líderes em suas especialidades. A equipe do Beneficiamento de carvão estagiou e foi treinada na WEDAG, em Bochum/Alemanha. A equipe da redução direta estagiou e foi treinada na LURGI, em Frankfurt, tendo também visitado outros fornos rotativos em operação.

As equipes da aciaria, forjaria, laminação e acabamento estagiaram e foram treinadas na $A B$ BOFORS, em Karlskoga/Suécia, numa operação extremamente bem sucedida de transferência de know-how, na complexa área de produção de aços especiais.

Com a unidade de redução em operação, muitas empresas interessadas no processo estagiaram na Piratini, entre elas a ISCOR, da África do Sul, e a SIIL Sponge Iron of India Limited. Quando da posta em marcha das unidades da ISCOR, o gerente da unidade da AFP lá esteve por cerca de um ano, prestando assistência.

No $2^{\circ}$ semestre de 1974 as empresas alemãs Mannesmann AG, Rheinische Braunkohlenwerke AG, Rheinisch-Westfälisches Elektrizitätswerk AG e LURGI Chemie und Hüttentechnik $\mathrm{GmbH}$, uniram-se à AFP para um teste industrial de emprego de briquetes de linhito alemão. Chegaram a Charqueadas $5.000 \mathrm{t}$ desses briquetes, que continham $42 \%$ de matéria volátil e $18 \%$ de água, porém com baixo teor de cinza. Os testes foram realizados de 3 a 19 de dezembro de 1974, tendo sido muito bem sucedidos. Foram utilizadas $4.400 \mathrm{t}$ de pelotas, consideradas de baixa qualidade pela equipe alemã, e $3.400 \mathrm{t}$ de briquetes de linhito. Foram produzidas $2.800 t$ de ferro esponja, com metalização média de $94 \%$ - índice extraordinário!

Os relatos da experiência podem ser encontrados em $[9,10]$.

Em 1975/6 foram testadas com êxito 12.000 t de minério de ferro de Corumbá/MS, que chegaram até Charqueadas pela seguinte rota: Corumbá/Nueva Palmira (Uruguai) por via fluvial; Nueva Palmira/Rio Grande, por via oceânica (Docenave); e Rio Grande/Charqueadas, por via lacustre/fluvial.

Em 1982 foi testado carvão energético de Santa Catarina que, por ser menos reativo, apresentou desempenho inferior ao do carvão não coqueificável do RS.

Essa pequena resenha histórica sublinha os seguintes aspectos:

- O carvão nacional apresenta uma bem sucedida experiência de emprego siderúrgico em escala industrial.

- Essa bem sucedida experiência não apenas se refletiu em uma série de novos conhecimentos técnicos em âmbito nacional, mas atraiu grande

* Contribuição técnica ao 44 Seminário de Redução de Minério de Ferro e Matérias-primas, $15^{\circ}$ Simpósio Brasileiro de Minério de Ferro e $2^{\circ}$ Simpósio Brasileiro de Aglomeração de Minério de Ferro, 15 a 18 de setembro de 2014, Belo Horizontze MG, Brasil. 
intercâmbio internacional, com ganhos tecnológicos recíprocos, inclusive na área acadêmica.

\section{ALGUNS EXEMPLOS EM OUTROS PAÍSES DE PRODUÇÃO DE FERRO ESPONJA A REDUTOR SÓLIDO}

O Peru mantém em operação 3 fornos rotativos, sendo 2 na Aceros Arequipa S.A.

A New Zealand Steel, uma usina para 650.000 t/ano de aço, opera quatro fornos rotativos, que utilizam como minério de ferro um minério de ferro fino (areia), extraído numa praia próxima à usina.

$\mathrm{Na}$ Índia, o primeiro forno SL/RN da SIIL foi construído no início da década de 80, com o auxilio da UNIDO, e a equipe da SIIL foi treinada na AFP. Essa unidade serviu de modelo para todas as numerosas unidades em operação e em construção naquele país. Aliás, é possível presumir que as unidades produtoras de ferro esponja a carvão na Índia terão a mesma importância que os produtores independentes de gusa têm no Brasil. Estudo distribuído no Seminário de Fusão, Solidificação e Refino de Aço, ocorrido em Vitória, em 2005, informa que a Tata Sponge e a Monnet Ispat, estariam indo, cada uma, para 1 milhão de t/ano de ferro esponja.

\subsection{Produção Mundial de Ferro Esponja $[17,18]$}

A produção mundial de ferro esponja tem aumentado significativamente no mundo, conforme a tabela abaixo, que também apresenta as participações da Índia e do Brasil.

Tabela 3. Produção de Ferro Esponja (DRI/HBI) no Mundo, na Índia e no Brasil.

\begin{tabular}{|c|c|c|c|c|c|}
\hline Ano & Total & $\begin{array}{c}\text { Na India } \\
{[1,2]}\end{array}$ & $\begin{array}{c}\text { India/Total } \\
(\%)\end{array}$ & No Brasil [3] & $\begin{array}{c}\text { Brasil/Total } \\
(\%)\end{array}$ \\
\hline 1980 & 7.427 & 10 & 0,1 & 275 & 3,7 \\
\hline 1985 & 11.172 & 102 & 0,9 & 285 & 2,6 \\
\hline 1990 & 19.323 & 610 & 3,1 & 260 & 1,4 \\
\hline 1995 & 32.049 & 4.267 & 13,3 & 288 & 0,9 \\
\hline 2000 & 43.240 & 5.498 & 12,7 & 412 & 1,0 \\
\hline 2004 & 55.157 & 9.121 & 16,5 & 440 & 0,8 \\
\hline 2008 & 66.014 & 20.916 & 31,7 & 302 & 0,5 \\
\hline 2010 & 70.015 & 24.831 & 35,5 & - & - \\
\hline 2012 & 70.937 & 19.677 & 27,7 & - & - \\
\hline \multicolumn{7}{|c|}{ Fontes: WSA (World Steel Association) e IABr } \\
\hline
\end{tabular}

(1) A Índia é atualmente o maior produtor mundial de ferro esponja. $67 \%$ de sua produção provêm de fornos rotativos, usando como redutor carvão mineral não coqueificável.

(2) Na Índia está sendo instalada uma unidade de redução direta à base de gás de topo de unidade COREX. Esse é outro exemplo de utilização de carvão mineral não coqueificável em siderurgia: primeiro produzindo gusa, pelo processo COREX; e em seguida usando o gás de topo do COREX para produzir ferro esponja pelo processo MIDREX. Note-se que isso é feito por empresas privadas, lucrativas, e sem subsídios oficiais.

(3) No Brasil os únicos produtores de ferro esponja eram a PIRATINI e a USIBA - a primeira usando como redutor o carvão mineral do $\mathrm{RS}$, com produção descontinuada em 1990; a USIBA, utilizando gás natural, com produção 
descontinuada em 2010. Em ambos os casos a produção foi descontinuada por razões econômicas - razões que se modificam ao longo dos anos.

\section{MODELO DE MINI USINA SIDERÚRGICA INTEGRADA COM BASE EM FERRO ESPONJA PRODUZIDO COM CARVÃO NACIONAL NÃO COQUEIFICÁVEL [19]}

A título de exemplo apresenta-se um modelo de usina siderúrgica integrada, com base na bem sucedida tecnologia da AFP, com as seguintes características: Produção de semiacabados de aço, de 1,2 milhões de t/a, a partir de uma carga metálica de 1,49 milhões de t/a, sendo 0,97 mt/a de ferro esponja e 0,52 de outros metálicos.

Para produção de 970.000 t/a de ferro esponja são necessárias 1,1 milhões de t/a de carvão redutor, obtidos a partir do beneficiamento de 3,14 milhões de toneladas de carvão run of mine (ROM). No beneficiamento do carvão ROM são produzidas também 1,1 milhões de $\mathrm{t}$ de carvão termelétrico de $3.100 \mathrm{kcal} / \mathrm{kg}$. Uma usina termelétrica (UTE) de $140 \mathrm{MW}$ poderá ser instalada a partir das 1,1 milhões de t/a de carvão termelétrico, enquanto outra UTE, de $56 \mathrm{MW}$, poderá operar com os gases de saída dos fornos rotativos. Com isso, a usina siderúrgica será integralmente autosuficiente em termos de redutor e de energia elétrica.

Tendo em vista as reservas de carvão não coqueificável do RS o horizonte de operação do modelo proposto, usando a tecnologia desenvolvida na AFP, é bastante superior a 100 anos.

Nos cálculos abaixo foram utilizados os índices obtidos nas Unidades de Beneficiamento de Carvão e de Redução Direta da AFP, não sendo consideradas melhorias que certamente teriam ocorrido se as unidades estivessem em operação até hoje.

Tabela 4. Produção de semiacabados de aço e a carga metálica

\begin{tabular}{|c|c|}
\hline Item & $10^{3} \mathrm{t} / \mathrm{a}$ \\
\hline Semiacabados & 1.200 \\
\hline Aço Líquido & 1.250 \\
\hline Carga Metálica & 1.490 \\
\hline $65 \%$ Ferro Esponja & 970 \\
\hline $35 \%$ Outros metálicos & 520 \\
\hline
\end{tabular}

Fonte: MINITEC

Conhecida a necessidade de ferro esponja, a Tabela 5 informa as quantidades de carvão necessárias.

Tabela 5. Quantidades de Carvão Mineral Não Coqueificável.

\begin{tabular}{|c|c|}
\hline Tipo de Carvão & $10^{3} \mathrm{t} / \mathrm{a}$ \\
\hline Carvão Redutor 1,05 x 970 & 1.100 \\
\hline Carvão ROM 1.100/0,35 & 3.143 \\
\hline $\begin{array}{c}\text { Carvão Termelétrico } \\
\text { (3.100 kcal/kg) }\end{array}$ & 1.100 \\
\hline Rejeitos e Perdas & 943 \\
\hline Fonte: Relatórios Internos da AFP e [19]
\end{tabular}

A Tabela 6 mostra a produção de energia elétrica que o Modelo proposto permite. 
Tabela 6. Produção de Energia Elétrica com os gases de saída dos fornos rotativos

\begin{tabular}{|c|c|c|}
\hline Item & Unidade & Produção \\
\hline Energia nos fumos & $10^{3} \mathrm{Gcal} / \mathrm{a}$ & 2.127 \\
\hline Geração de energia $(\mathrm{n} \approx 20 \%)$ & $10^{3} \mathrm{MWh} / \mathrm{a}$ & 457 \\
\hline Potência (com 8.160 h/a) & $\mathrm{MW}$ & 56 \\
\hline \multicolumn{2}{|c|}{ Fonte: MINITEC }
\end{tabular}

A Tabela 7 apresenta a produção de energia elétrica com 1,1 milhões de t/ano de carvão termelétrico de $3.100 \mathrm{kcal} / \mathrm{kg}$.

Tabela 6. Geração de Energia Elétrica com 1,1 milhões de t/ano de C.T.

\begin{tabular}{|c|c|c|}
\hline Item & Unidade & Produção \\
\hline Energia no Carvão Termeletr. & $10^{3} \mathrm{Gcal} / \mathrm{a}$ & 3.410 \\
\hline $\begin{array}{c}\text { Geração de Energia. Elétrica } \\
(\eta \approx 30 \%)\end{array}$ & $10^{3} \mathrm{MWh} / \mathrm{a}$ & 1.180 \\
\hline Potência com 8.160 h/a & MW & 145 \\
\hline \multicolumn{2}{|c|}{ Fonte: MINITEC } \\
\hline
\end{tabular}

Assim, a potência total instalada é de $145+56=201 \mathrm{MW}$ e a oferta de energia elétrica é de $(457+1180) \times 0,9=1.473 .000 \mathrm{KWA} / \mathrm{ano}$

A Tabela 8 apresenta o Balanço entre Geração e Consumo de Energia Elétrica no Modelo proposto.

Tabela 7. Balanço entre Geração e Consumo de Energia Elétrica.

\begin{tabular}{|c|c|}
\hline Item & $10^{3} \mathrm{MWh} / \mathrm{a}$ \\
\hline Oferta & $\underline{1.473}$ \\
\hline Consumo & $\underline{1.227}$ \\
\hline $\begin{array}{c}\text { Beneficiamento de Carvão } \\
\text { e na Un, de Red. Direta }\end{array}$ & 242 \\
\hline Aciaria: $1.240 .000 \times 0,7$ & 868 \\
\hline Outros (10\%) & 117 \\
\hline Para venda & 246 \\
\hline
\end{tabular}

Em termos práticos o Modelo proposto é autosuficiente em energia elétrica, com significativa sobra para comercialização.

\section{OUTRAS POSSIBILIDADES DE EMPREGO DO CARVÃO MINERAL DO RS EM SIDERURGIA}

\subsection{Injeção de Carvão Pulverizado nos Altos Fornos a Coque}

O LaSid da EEUFRGS tem realizado estudos e experiências, algumas em parceria com a Universidade Técnica de Aachen/Alemanha, sobre o emprego de finos de carvão mineral do RS para injeção pelas ventaneiras de altos fornos a coque $(\mathrm{PCl}$ Pulverized Coal Injection) - em substituição ao carvão mineral importado.

Esses estudos e experiências têm sido apresentados em diversos eventos, inclusive da ABM $[20,21]$.

No ano de 2012 a média de injeção de finos de carvão mineral nos altos fornos a coque foi da ordem de $120 \mathrm{~kg}$ por t de gusa, e a produção de gusa a coque foi de 24,6 milhões de toneladas. O IABr também informou que em 2012, para PCI, foram importadas 2,8 milhões de t de carvão mineral. 


\subsection{Redutor no Processo COREX}

O carvão não coqueificável do RS já foi usado com inteiro sucesso, em mistura com carvão metalúrgico de Santa Catarina, em teste industrial que a VALE (então CVRD) fez realizar na unidade de demonstração industrial do Processo COREX (ex KR), em Kehl/ Alemanha [21]. O Processo COREX produz gusa usando diretamente carvão mineral, sem prévia coqueificação

\subsection{Redutor no Processo TECNORED}

A VALE, através de sua subsidiária TECPAR, está desenvolvendo o novo processo de redução TECNORED, na unidade piloto instalada em Pindamonhangaba/SP. O processo se caracteriza pelo emprego de carvão redutor e de minério, ambos finos, aglomerados em briquetes autoredutores, produzindo gusa, com pequena quantidade adicional de coque. O Processo TECNORED poderá fazer uso intenso do carvão mineral não coqueificável do RS.

Nota: Este trabalho não contempla as reservas de carvão coqueificável de Morungava, Chico Lomã e Santa Teresinha, já identificadas e medidas, mas ainda não exploradas.

\section{PERSPECTIVAS}

As perspectivas de emprego do Carvão Mineral não coqueificável do RS, do ponto de vista técnico, são amplamente favoráveis - o presente trabalho identifica diversos processos em que essa alternativa foi comprovada, em escala industrial ou piloto. A alternativa mais impactante é a do Processo SL/RN, operado durante 17 anos pela Aços Finos Piratini SA. O Modelo de Mini Usina Siderúrgica Integrada com base em ferro esponja produzido com carvão não coqueificável do RS ilustra bem essa perspectiva, embora carecendo ainda do desenvolvimento dos aspectos econômicos atualizados, quais sejam, a orçamentação do investimento e a análise do custo operacional e do retorno do investimento. O grande óbice à concretização desse modelo ainda é a logística, afetada pela deficiente infraestrutura de transporte no Brasil - notadamente o ferroviário e o de cabotagem. O minério de ferro se localiza em Minas Gerais, no Mato Grosso do Sul e no norte do país, enquanto o carvão se encontra no extremo sul. Como resultado, o frete de uma tonelada de carvão do RS ao centro ou ao norte do país custa atualmente mais que o frete da tonelada de carvão vindo da Austrália para os mesmos destinos. E o frete de uma tonelada de minério de Tubarão ou do Porto da Madeira à China custa menos do que o transporte desde esses mesmos portos ao porto de Rio Grande/RS.

O documento "Roadmap Tecnológico para produção, uso limpo e eficiente do carvão mineral nacional: 2012 a 2035", do CGEE [22], à página 35, relaciona as seguintes metas:

(i) Meta até 2022 - Processo de Redução Direta desenvolvido para carvão mineral não coqueificável de alto teor de cinza.

Para cumprir essa meta basta repetir, atualizando, o que foi feito no passado, aqui relatado, e que se encontra consolidado nos estudos e experiências, projeto, construção e operação da Aços Finos Piratini SA, nas décadas de 1960 e 1970.

(ii) Meta até 2022 - Processo de fusão-redução desenvolvido para carvão não coqueificável.

O caminho já parcialmente desbravado é apontado pela experiência bem sucedida que a CVRD, hoje VALE, realizou em 1988, com mistura de carvão metalúrgico de Santa Catarina e carvão energético do Rio Grande do Sul, na unidade semi-

* Contribuição técnica ao 44 Seminário de Redução de Minério de Ferro e Matérias-primas, 15은 Simpósio Brasileiro de Minério de Ferro e 2ํ Simpósio Brasileiro de Aglomeração de Minério de Ferro, 15 a 18 de setembro de 2014, Belo Horizontes ${ }_{3}$ MG, Brasil. 
industrial de 75.000 t/a de Kehl/Alemanha [21]. Todas as unidades COREX no mundo operam com carvões não coqueificáveis, com uma pequena adição de coque.

Para cumprir esta meta dever-se-á repetir e aprofundar o que já foi iniciado, em fins da década de oitenta - sem esperar pela terceira década do nosso século.

(iii) Meta até 2035 - Técnicas desenvolvidas para utilização de carvão mineral nacional gaseificado em processos de redução direta

De 1976 a 1982 foi desenvolvido em Santa Catarina o Projeto SIDERSUL, com tecnologia ditada pelo então CONSIDER: "Apoiar a implantação em Santa Catarina de uma usina siderúrgica de 500.000 t/ano integrada a redução direta, usando carvão mineral local gaseificado" Essa usina deveria ter sido implantada próximo do Porto de Imbituba/SC. Firmas de engenharia nacional com o apoio da FINEP, do BRDE Banco Regional de Desenvolvimento do Extremo Sul, da SUDESUL Superintendência de Desenvolvimento do Sul (órgão do Ministério do Interior), do Governo de Santa Catarina, da iniciativa privada de Santa Catarina e mesmo de empresas do exterior, , além de terem realizado o estudo conceitual e de viabilidade técnica e econômica, executaram também a Engenharia Básica. A gaseificação se faria pelo Processo LURGI e a redução direta pelo processo MIDREX. O projeto, embora técnica e economicamente viável, não foi implantado, mas continua apontando o caminho tecnológico.

Para cumprir a meta bastará retomar e desenvolver aquilo que já foi feito nas décadas de 70 e 80 , sem necessidade de esperar pela quarta década do nosso século.

\section{CONCLUSÕES}

- Já existe no Brasil experiência comprovada em muitos anos de operação na produção de ferro esponja, tendo como redutor carvão não coqueificável de alto teor de cinzas, do RS

- O carvão não coqueificável do RS já participou com sucesso de experiência em escala semi-industrial, junto com o carvão metalúrgico de Santa Catarina, para a produção de gusa, pelo Processo COREX.

- Estudos do LaSid da EEUUFRGS mostram a viabilidade do uso de finos do carvão não coqueificável do RS na injeção pelas ventaneiras dos altos fornos a coque, substituindo o carvão mineral importado, ainda que parcialmente.

- Estudos até a nível de projeto básico, feitos nas décadas de 70 e 80, para implantação de uma usina siderúrgica com base na gaseificação de carvão para redução de minério de ferro, feitos com carvão metalúrgico de SC e carvão não coqueificável do RS, apontam o caminho para projeto similar com carvão mineral nacional

- Portanto, existem precedentes amplamente bem sucedidos de emprego de carvão não coqueificável do RS em siderurgia, em escala industrial e semiindustrial. Tecnicamente bastará retomar e atualizar economicamente o que foi feito no passado não tão distante.

\section{Agradecimento}

Os autores desejam prestar homenagem aos pioneiros já falecidos e que tanto fizeram em prol do carvão mineral nacional. Entre eles: Prof. Bernardo Geisel (UFRGS/AFP); Profa. Helena Leister (UFRGS/AFP); Dr. Willy C. Froehlich (Deputado Federal/AFP); Eng. Germano J. Andreis (AFP); Eng Ruy de A. Vilanova

* Contribuição técnica ao 44ํㅗㄴ Seminário de Redução de Minério de Ferro e Matérias-primas, 15오 Simpósio Brasileiro de Minério de Ferro e 2ํ Simpósio Brasileiro de Aglomeração de Minério de Ferro, 15 a 18 de setembro de 2014, Belo Horizontę4 MG, Brasil. 
(UFRGS/AFP); Eng. Ruy H. Rangel (SRSA/AFP); Eng. Henrique Anawate Catedrático de Siderurgia da UFRGS - Diretor da AFP - Grupo Gerdau - BRDE SERGS - duas vezes Secretário de Energia, Transportes e Comunicação do Rio Grande do Sul: Dr. Roberto G. de Faria (Copelmi); Eng. Ney W. Araujo Secretário Geral do MME, Eng Romulo Machado (CRM); Eng. Arthur W. Schneider (CRM); Prof. Anildo Bristoti (UFRGS/PPGEM); Eng. Augusto Baptista Pereira (minerador de carvão em Santa Catarina e Secretário de Tecnologia e Meio Ambiente daquele Estado).

\section{REFERÊNCIAS}

1 Brasil. Ministério de Minas e Energia. Balanço energético nacional 2004. Brasília, 2004.

2 Geisel B. A gaseificação do carvão mineral do Rio Grade do Sul. In: Conferência Científica da Associação Brasileira de Metais, 16, 1961, Porto Alegre. Boletim da Associação Brasileira de Metais, v.17, n.6, p.905-924, nov. 1961.

3 Pfeifer HC. Processos de redução direta: Análise comparativa de diversos processos do ponto de vista econômico, com vistas a seu emprego no Rio Grande do Sul. In: Congresso Anual da Associação Brasileira de Metais, 1962, Rio de Janeiro. Boletim da Associação Brasileira de Metais, 1963; 19(74): 5-64.

4 Leister H, Villanova R, Andreis G. Refratariedade das cinzas de carvões do Estado do Rio Grande do Sul. In: Congresso da ABM, 21, 1966, Volta Redonda. Metalurgia ABM, 1966; 22(108): 877-882.

5 Moeller A, Villanova R, Leister H, Balinski A. Processo SL/RN - Ensaios com matérias primas nacionais. In: CONGRESSO DA ABM, 21,1966, Volta Redonda. Metalurgia ABM, v.23, n.11, p.127-135, fev. 1967.

6 Geisel B, Pfeifer HC, Villanova RA, Leister H, Balinski A. Sucata ou ferro esponja? A solução de Aços Finos Piratini S.A. In: Congresso Anual da ABM, de Julho, 1969, São Paulo. Metalurgia ABM, v. 25, n.145, p.937-949, dez. 1969.

7 Scherer SWG. Sucata e ferro esponja: solução para o Brasil, exclusivamente com matérias-primas nacionais. In: Congresso Anual da ABM, 26, 1971, Rio de Janeiro. Metalurgia ABM, v. 28, n.174, p.323-330, maio 1972.

8 Pfeifer H, Scherer SWG. Redução direta de minério de ferro - Processo SL/RN. In: Congresso Anual da ABM, 27, 1972, São Paulo, Metalurgia, v.28, n. 181, p. 861-873, dez. 1972.

9 Scherer SWG, Pfeifer HCP; Balinski A. Ferro Esponja no Brasil - Processo

SL/RN a Redutor Sólido - Da Ideia aos Resultados. In: ILAFA Reducción Directa en America Latina. Cidade do México. Novembro 1973.

10 Memória do Seminário do ILAFA, Tomos I e II, sobre "A Redução de Minério de Ferro: Estado Atual e Perspectivas" e "III Simpósio da ABM sobre Eletro Siderurgia - Porto Alegre, 04 a 09 de Maio de 1975

11 Grebe K. Manufacture of highly metallized sponge iron from Brazilian ore with rhenish lignite in the SL/RN Rotary Kiln of AFP. In: SEMINÁRIO DO ILAFA, 1975, Porto Alegre.

12 Rangel $\mathrm{RH}$. O balanço energético e a quantificação da transferência de massa de uma unidade SL/RN. In: SEMINÁRIO DO ILAFA, 1997, Macuto, Venezuela.

13 Rangel RH. Resultados alcançados pela AFP em sua planta SL/RN. In: Seminário do ILAFA, 1980, Buenos Aires.

14 Scherer SWG. Ferro esponja: Perspectivas de Fabricação e Uso. Metalurgia ABM, v.37, n. 279, p.70-76, fev. 1981.

15 Aspectos operacionais na utilização de ferro esponja na AFP. In: LURGI - Family Meeting. 1981, Porto Alegre.

16 Andreis G, Zimmer M. O carvão mineral do R.G. do Sul e suas perspectivas. In: Seminário Sobre Alternativas para Utilização de Carvão Mineral na Siderurgia A Coque, 1984, Volta Redonda.

17 WSA World Steel Association

* Contribuição técnica ao 44ํㅗㄴ Seminário de Redução de Minério de Ferro e Matérias-primas, 15은 Simpósio Brasileiro de Minério de Ferro e 2ํ Simpósio Brasileiro de Aglomeração de Minério de Ferro, 15 a 18 de setembro de 2014, Belo Horizontegs MG, Brasil. 
18 IABr Instituto Aço Brasil

19 Scherer SWG, Pfeifer HCP. Modelo Siderúrgico à Base de Ferro Esponja Produzido com Carvão Mineral Nacional Não Coqueificável. In: XXXV Seminário da ABM sobre Redução de Minério de Ferro. 2006. Florianópolis/SC

20 Coletânea de trabalhos do LaSid do Centro Tecnológico da EEUFRGS na Área de Utilização do Finos de Carvão Mineral Nacional pelas ventaneiras dos altos fornos. Como também as Teses de Mestrado, na Área de Redução Direta, lá desenvolvidas.

21 Scherer, SWG; Pfeifer, HCP. Modelos Siderúrgicos à Base de Ferro Gusa Produzido com Carvão Mineral Nacional. In: XXXV Seminário da ABM sobre Redução de Minério de Ferro. 2006. Florianópois/SC

22 CGEE Centro de Gestão e Estudos Estratégicos do MDIC. Roadmap tecnológico para produção, uso limpo e eficiente do carvão mineral nacional: 2012 a 2035. In: Série Documentos Técnicos. Novembro 2012 - № 14.

* Contribuição técnica ao 44 Seminário de Redução de Minério de Ferro e Matérias-primas, 15은 Simpósio Brasileiro de Minério de Ferro e $2^{\circ}$ Simpósio Brasileiro de Aglomeração de Minério de Ferro, 15 a 18 de setembro de 2014, Belo Horizonța, MG, Brasil. 